Article

\title{
Reuso de Água de Drenagem Subterrânea em Canteiro de Obras e para Irrigação de Jardins: Um Estudo de Caso em Fortaleza-CE
}

\author{
Camila Mareco de Sousa ${ }^{1}$ (D), Cleiton da Silva Silveira ${ }^{2}$, Emerson Mariano da Silva $^{1}$ (D), \\ Roberto José Almeida de Pontes ${ }^{1}$ \\ ${ }^{1}$ Mestrado Profissional em Climatologia e Aplicações nos Países da CPLP a África, Universidade \\ Estadual do Ceará, Fortaleza, CE, Brasil. \\ ${ }^{2}$ Programa de Pós-Graduação em Engenharia Civil, Departamento de Engenharia Hidráulica e \\ Ambiental, Universidade Federal do Ceará, Fortaleza, CE, Brasil.
}

Recebido em: 15 de Fevereiro de 2021 - Aceito em: 1 de Maio de 2021

\begin{abstract}
Resumo
A pesquisa consiste em um estudo de caso que possui como cenário o canteiro de obras de um edifício residencial multifamiliar localizado na cidade de Fortaleza- Ceará. Para este fim, foram levados em consideração parâmetros da Portaria de Consolidação $N^{\circ} 5$ (para o caso de água potável), requisitos da norma ABNT NBR 15900-1/2009, no caso de água com interação com cimento, além de critérios estabelecidos na Resolução CONAMA No 375, para o caso de água para irrigação de jardins. Para o uso em atividades que exigem potabilidade, a água do sistema de rebaixamento não se mostrou viável tecnicamente. Já para o seu reuso em outras atividades do canteiro de obras, como fabricação de concretos e argamassas e outras que não exigem requisitos mínimos, o reuso da água gerou uma economia de $\mathrm{R} \$ 225.869,04$, representando $0,21 \%$ no orçamento da obra. Além disso, para o reuso no sistema de irrigação dos jardins do condomínio, gerou uma economia mensal estimada de 294 metros cúbicos de água e R \$ 8.437,92. Além de gerar economia ao empreendimento durante sua construção e durante sua vida útil pós-entrega, o reuso dessa água de drenagem possibilita a não utilização de água potável em atividades não nobres.
\end{abstract}

Palavras-chave: reuso de água, drenagem subterrânea, canteiro de obras, irrigação.

\begin{abstract}
The research consists of a case study with the construction site of a multifamily residential building located in the city of Fortaleza-Ceará. For this purpose, parameters of Consolidation Ordinance $\mathrm{N}^{\circ} 5$ (for drinking water), requirements of ABNT NBR 15900-1 / 2009, in the case of water interacting with cement, in addition to criteria established in Resolution CONAMA No 375, in the case of water for garden irrigation. For use in activities that require potability, the water from the lowering system was not technically feasible. As for its reuse in other activities of the construction site, such as concrete and mortar manufacturing and others that do not require minimum requirements, the reuse of water generated savings of $\mathrm{R} \$ 225,869.04$, representing $0.21 \%$ in the construction budget. In addition, for the reuse of the irrigation system in the condominium gardens, it generated an estimated monthly savings of 294 cubic meters of water and $\mathrm{R} \$ 8,437.92$. In addition to generating savings for the project during its construction and during its post-delivery life, the reuse of this drainage water makes it possible to not use drinking water for non-noble activities.
\end{abstract}

Keywords: water reuse, underground drainage, construction site, irrigation.

\section{Introdução}

A indústria da construção civil é um setor que apresenta uma grande demanda por água, utilizando-a em diversas etapas construtivas e na fabricação de materiais, mesmo assim, as ações tomadas para a sua racionalização e combate ao seu desperdício ainda não se popularizaram nos canteiros de obras. Por este motivo, a adoção de medidas que visam diminuir o consumo de água ou reaproveitá-la em local apropriado tem sido um tema bastante abordado (Mancuso e Santos, 2003).

Autor de correspondência: Camila Mareco de Sousa, camilamareco@gmail.com. 
Praticamente todas as atividades dentro de um canteiro de obras necessitam de água, seja para preparação do local (limpeza prévia), composição e mistura de materiais, até consumo humano em bebedouros e vestiários etc. A água é um dos insumos mais consumidos no processo construtivo, cerca de $280 \mathrm{~m}^{3}$ por mês, em média, segundo Marques, Gomes e Brandli (2017), para uma obra com características semelhantes à deste estudo de caso. No entanto, o estudo realizado pelos mesmos autores não destaca que volume desse consumo total corresponde a consumo humano, pois as obras analisadas utilizavam água fornecida pela concessionária para todas as atividades do canteiro.

A Lei 9.433/1997, que rege a Política Nacional de Recursos Hídricos (BRASIL, 1997), diz que a água é considerada um recurso natural limitado de domínio público e dotada de valor econômico, cujo uso deve ser feito de forma racional visando o desenvolvimento sustentável assegurando assim à atual e às futuras gerações a disponibilidade de água. Portanto, é importante difundir a ideia de sustentabilidade em relação ao seu uso através de melhorias tecnológicas nos processos industriais e incentivos na reutilização da água, evitando ao máximo o seu desperdício para que não ocorram futuros problemas relacionados à sua escassez.

O aproveitamento e reuso da água de uma edificação vem se tornando uma das opções mais rentáveis para a racionalização de água, em virtude de ser uma técnica segura e confiável. Diversas etapas da construção civil poderiam se beneficiar do reuso e uso racional da água. Pode-se destacar, por exemplo, as atividades que envolvem a escavação do solo para a execução de fundações e estruturas de subsolo (CBIC, 2017). Porém, é necessária a aprovação do mercado econômico e incentivo governamental para a sua maior difusão e reconhecimento, a fim de que se torne uma tecnologia sustentável cada vez mais acessível e viável (Telles e Costa, 2010).

Diante do panorama exposto, este trabalho pretende contribuir para que novas ideias e tecnologias sejam desenvolvidas e aplicadas no reuso consciente de água, principalmente em atividades industriais que não necessitam de água potável. As obras de construção civil apresentam características que permitem o aproveitamento de água subterrânea.

O principal objetivo desta pesquisa foi avaliar o potencial de reuso da água de drenagem subterrânea em um condomínio de edifícios em construção, na cidade de Fortaleza-CE, possibilitando a redução do consumo de água potável fornecida pela concessionária, promovendo sustentabilidade ao empreendimento.

\section{Metodologia}

O local deste estudo de caso é o canteiro da obra de execução de um condomínio vertical, residencial, multifamiliar, composto por duas torres de 22 pavimentos. Cada torre tem 176 apartamentos e 02 subsolos, destinados ao estacionamento de veículos. A área comum é composta por: piscina de adultos e infantil, deck, quadra poliesportiva, salão de jogos, academia, hall social e playground, além de cerca de $1.700 \mathrm{~m}^{2}$ de jardins. O empreendimento localiza-se no bairro Papicu, na cidade de Fortaleza/CE, em um terreno com área total de $11.336,42 \mathrm{~m}^{2}$ e uma área construída de $53.039,50 \mathrm{~m}^{2}$. A Fig. 1 identifica a planta baixa de situação do empreendimento.

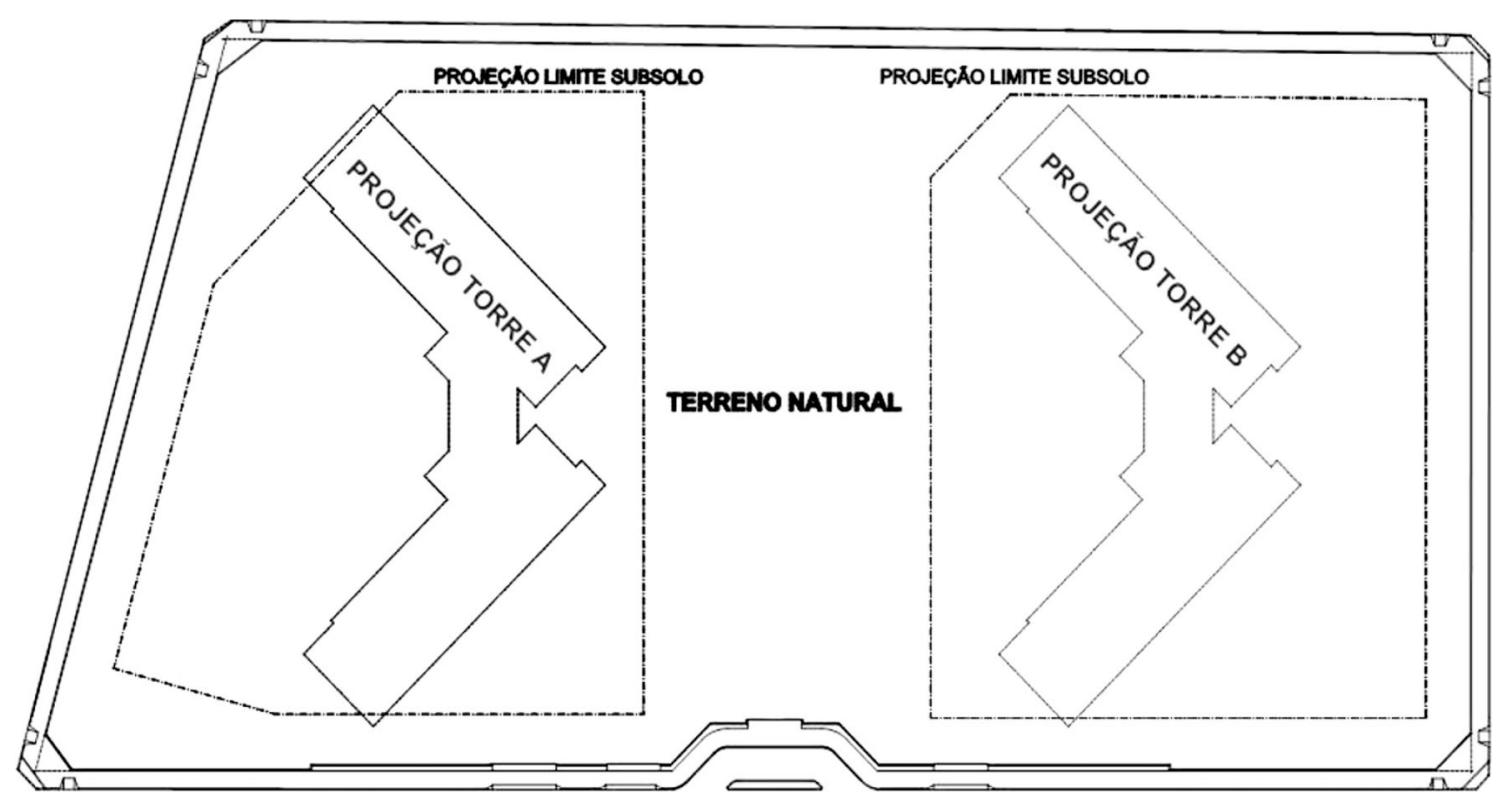

Figure 1 - Planta baixa de situação da obra. Fonte: Adaptado de projetos fornecidos pela construtora (2019). 
Para verificar se a água proveniente da drenagem subterrânea de um condomínio residencial pode ser reutilizada nos serviços de um canteiro de obras, a fim de gerar economia e reduzir o consumo de água tratada, durante a construção de um empreendimento residencial e, após a entrega do empreendimento, na irrigação dos jardins desse condomínio, foi realizado um estudo de caso para avaliação técnica da água e a viabilidade econômica de seu reuso. Conforme Fig. 2.

O primeiro passo adotado foi a análise laboratorial de amostras da água, para verificar se a mesma poderia ser qualificada como potável, pois em caso positivo, ela seria liberada para uso em quaisquer dos serviços do canteiro de obras. Em caso negativo, não poderia ser realizada a sua aplicação em atividades que envolvem consumo humano, como em bebedouros, vestiários e refeitórios.
Ainda para a hipótese de a água não ser qualificada como potável, dentro do contexto do seu reuso no canteiro de obras, faz-se necessário verificar a sua qualificação para utilização no amassamento de concretos e argamassas. Para isso, é preciso realizar ensaios laboratoriais qualificando a água dentro dos requisitos da ABNT NBR 15.9001/2009- Água para amassamento de concreto- Parte 1: Requisitos. Em caso de aprovação, a água poderá ser utilizada para este fim. Em caso negativo, seu reuso deverá ser vetado para essas atividades. Nesse caso, ela apenas poderá ser reutilizada em atividades que não exigem nenhuma qualificação para a água, como compactação de aterros e limpeza de pisos e equipamentos.

Para a hipótese de reuso na irrigação dos jardins do condomínio, após sua fase de construção, a água desqualificada para uso potável, também precisa ser verificada conforme critérios da Resolução CONAMA No 375, de 17

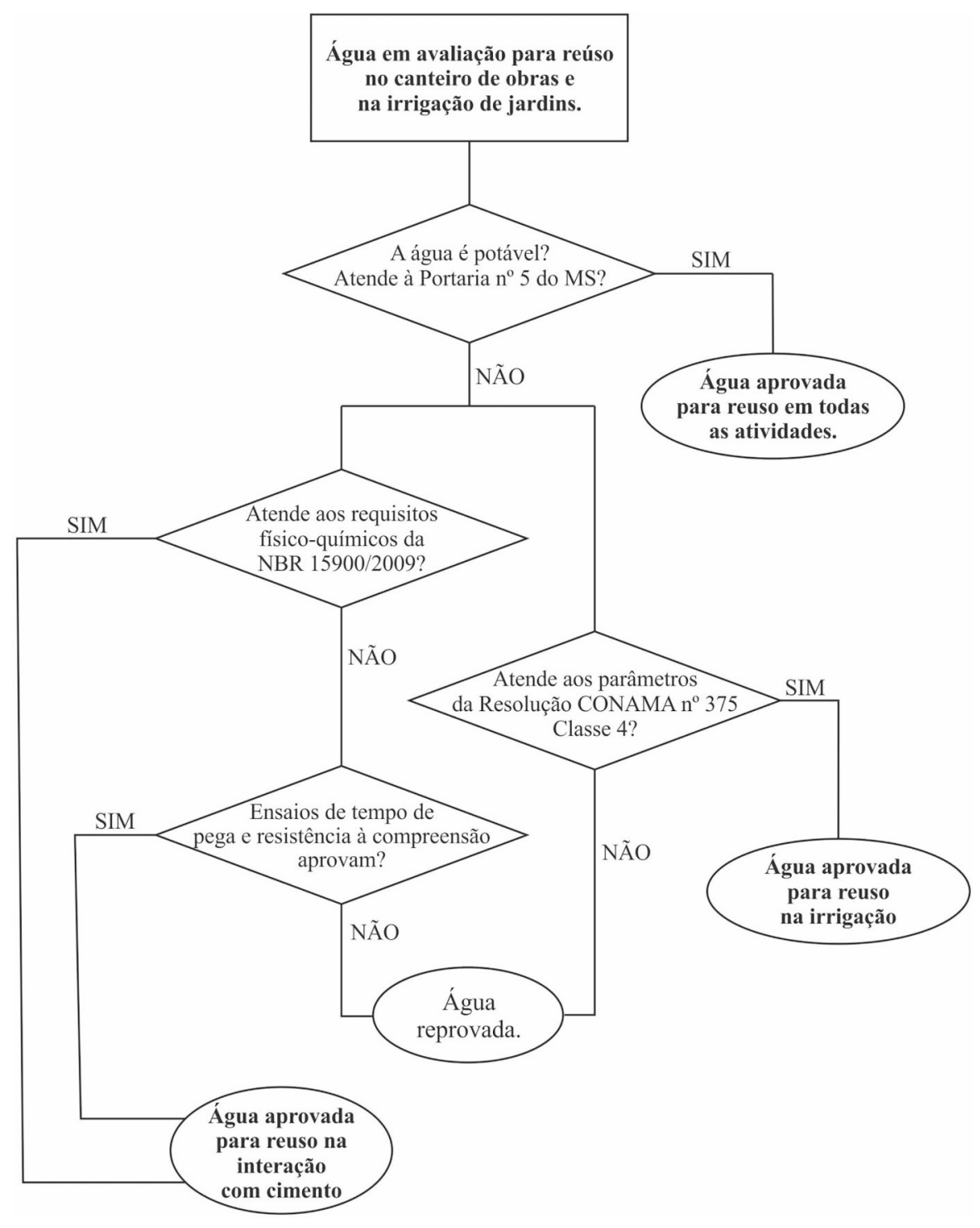

Figure 2 - Fluxograma de análise da qualidade da água. 
de março de 2005. Em caso positivo, seu reuso em irrigação de jardins poderá ser liberado. Caso contrário, haveria um custo de tratamento para ajuste desses indicadores.

\subsection{Aproveitamento da água no canteiro de obras}

Para verificar se a água de drenagem poderia ser utilizada nas atividades do canteiro, foi necessário analisar a sua composição microbiológica e físico-química com a finalidade de verificar se ela estava dentro dos parâmetros necessários para ser aproveitada no consumo humano - vestiários, refeitório e bebedouros - e nas interações com cimento: fabricação de concretos e argamassas. Esses dois casos são os que tem alguma exigência normativa ou legislativa. No caso do consumo humano, a Portaria de Consolidação $\mathrm{N}^{\circ} 5$ de 2017 do MS e, no caso da interação com o cimento, a ABNT NBR 15.900-1/2009- Água para amassamento de concretoParte 1: Requisitos.

O Ministério do Meio Ambiente (2020) sugere que uma pessoa consome por dia cerca de $40 \mathrm{~L}$ de água para realizar as seguintes atividades: beber, tomar banho, escovar os dentes, lavar as mãos e cozinhar. A partir dessa informação, pode-se considerar que, dos $280 \mathrm{~m}^{3}$ de água consumidos por mês, aproximadamente $48 \mathrm{~m}^{3}$ são de água potável, considerando um efetivo médio de 60 pessoas e 20 dias úteis por mês $(60$ pessoas $\times 40$ litros de água por dia $\times 20$ dias $\left.=48.000 \mathrm{~L}=48 \mathrm{~m}^{3} / \mathrm{mês}\right)$. Assim, o volume de água não potável a ser consumida por mês, no canteiro deste estudo de caso, é de $280 \mathrm{~m}^{3}-48 \mathrm{~m}^{3}=232 \mathrm{~m}^{3}$ por mês.

Para determinar as características da água proveniente do sistema de drenagem, foram coletadas amostras para análise microbiológica e físico-química, realizada em laboratório licenciado, com relação aos valores de referência da Portaria $\mathrm{n}^{\circ} 5$ de 2017 do MS, mostrados na Tabela 1. Para a análise físico-química e organoléptica, foram considerados os requisitos da ABNT NBR 15.900-1, conforme dados do Tabela 2.

Para verificar a viabilidade econômica do reuso no canteiro de obras, foi realizada uma simulação de conta de cobrança, conforme diretrizes da concessionária mostradas no Tabela 3, onde o valor total da conta é o resultado da multiplicação do volume consumido pela tarifa correspondente. Para um consumo médio de $232 \mathrm{~m}^{3}$ por mês, considerando a categoria do cliente (industrial) e o valor proporcional para o consumo do volume de água conforme as faixas e o valor correspondente referente à coleta de esgoto, que a concessionária considera ser $80 \%$ do volume de água consumida.

Não houve custo de implantação do sistema de reuso, visto que o sistema de drenagem já fazia parte do projeto do empreendimento e que as tubulações de captação e distribuição, bem como reservatórios intermediários, já faziam parte das instalações previstas para o canteiro de obras. Além disso, foi acrescentado o custo periódico de
Tabela 1 - Requisitos de padrão da água para consumo humano.

\begin{tabular}{lc}
\hline $\begin{array}{l}\text { Descrição dos Valores de Referência da } \\
\text { Portaria } N^{\circ} 5 \text { de } 2017\end{array}$ & $\begin{array}{c}\text { Valores de Referência da } \\
\text { Portaria } N^{\circ} 5 \text { de } 2017\end{array}$ \\
\hline Cloretos & $250 \mathrm{mg} / \mathrm{L}$ \\
Cor Aparente & $15 \mu \mathrm{H}^{1}$ \\
Dureza Total & $500 \mathrm{mg} / \mathrm{L}$ \\
Ferro Total & Inferior à $0,3 \mathrm{mg} / \mathrm{L}$ \\
Nitrato & $10 \mathrm{mg} / \mathrm{L}$ \\
Nitrito & $1 \mathrm{mg} / \mathrm{L}$ \\
pH & $6,0 \mathrm{a} 9,5$ \\
Sódio & $200 \mathrm{mg} / \mathrm{L}$ \\
Sólidos Totais Dissolvidos & $1000 \mathrm{mg} / \mathrm{L}$ \\
Turbidez & $1 \mathrm{uT}{ }^{2}$ \\
Bactérias Heterotróficas & Inferior à $500 \mathrm{UFC} / \mathrm{mL}$ \\
Coliformes Termotolerantes & Ausência em $100 \mathrm{~mL}$ \\
Coliformes Totais & Ausência em $100 \mathrm{~mL}$ \\
\hline
\end{tabular}

Observações: (1) Unidade Hazen (mgPt-Co/L), (2) Unidade de Turbidez, (3) Unidade Formadora de Colônia.

Fonte: Adaptado de MS - Anexo XX, 2017.

Tabela 2 - Requisitos da ABNT NBR 15.900-1.

\begin{tabular}{lc}
\hline $\begin{array}{l}\text { Descrição dos requisitos da ABNT } \\
\text { NBR } 15900\end{array}$ & $\begin{array}{c}\text { Parâmetro requerido em norma } \\
(\mathrm{mg} / \mathrm{L})\end{array}$ \\
\hline Óleos e gorduras & $\begin{array}{c}\text { Não mais do que traços visíveis } \\
\text { Qualquer espuma deve } \\
\text { desaparecer em } 2 \text { min }\end{array}$ \\
Detergentes & Amarelo claro a incolor \\
Cor & $\leq 50.000$ \\
Material sólido & Inodoro \\
Odor & pH $\geq 5$ \\
Ácidos & padrão \\
Matéria orgânica & $\leq 500$ \\
Cloretos $($ concreto protendido) & $\leq 2.000$ \\
Sulfatos & $\leq 1.500$ \\
Álcalis & $\leq 100$ \\
Açúcares & $\leq 100$ \\
Fosfatos $\left(\mathrm{P}_{2} \mathrm{O}_{5}\right)$ & $\leq 500$ \\
Nitratos $\left(\mathrm{NO}_{3}\right)$ & $\leq 100$ \\
Chumbo $\left(\mathrm{Pb}^{2+}\right)$ & $\leq 100$ \\
Zinco $\left(\mathrm{Zn}^{2+}\right)$ &
\end{tabular}

Fonte: Adaptado da ABNT NBR 15.900-1 (2009).

ensaio laboratorial de amostras da água para monitoramento, conforme recomendado pela ABNT NBR 15900-1/ 2009.

\subsection{Aproveitamento da água na irrigação de jardins após a entrega do empreendimento}

Para verificar se o volume de água drenado é capaz de atender a demanda necessária para a irrigação dos jar- 
Tabela 3 - Tabela de tarifas de água e esgoto praticadas pela CAGECE a partir de 24 de março de 2019.

\begin{tabular}{|c|c|c|c|}
\hline Categoria & Faixa de consumo $\left(\mathrm{m}^{3}\right)$ & Tarifa água $\left(\mathrm{R} \$ / \mathrm{m}^{3}\right)$ & Tarifa esgoto $\left(\mathrm{R} \$ / \mathrm{m}^{3}\right)$ \\
\hline Residencial Social - Demanda máxima de $10 \mathrm{~m}^{3}$ água e $8 \mathrm{~m}^{3}$ esgoto & 0 a 10 & 1,38 & 1,38 \\
\hline \multirow[t]{5}{*}{ Residencial Popular - Demanda mínima de $10 \mathrm{~m}^{3}$ água e $8 \mathrm{~m}^{3}$ esgoto } & 0 a 10 & 2,83 & 2,83 \\
\hline & 11 a 15 & 4,82 & 4,82 \\
\hline & 16 a 20 & 5,23 & 5,23 \\
\hline & 21 a 50 & 8,99 & 8,99 \\
\hline & $>50$ & 16,02 & 16,02 \\
\hline \multirow[t]{5}{*}{ Residencial Normal - Demanda mínima de $10 \mathrm{~m}^{3}$ água e $8 \mathrm{~m}^{3}$ esgoto } & 0 a 10 & 4,03 & 4,46 \\
\hline & 11 a 15 & 5,23 & 5,72 \\
\hline & 16 a 20 & 5,65 & 6,2 \\
\hline & 21 a 50 & 9,69 & 10,65 \\
\hline & $>50$ & 17,11 & 18,82 \\
\hline Comercial Popular - Demanda mínima de $7 \mathrm{~m}^{3}$ água e $5 \mathrm{~m}^{3}$ esgoto & 0 a 13 & 4,82 & 5,31 \\
\hline \multirow[t]{2}{*}{ Comercial II - Demanda mínima de $10 \mathrm{~m}^{3}$ água e $8 \mathrm{~m}^{3}$ esgoto } & 0 a 50 & 10,1 & 11,16 \\
\hline & $>50$ & 16,02 & 17,62 \\
\hline \multirow[t]{3}{*}{ Industrial - Demanda mínima de $15 \mathrm{~m}^{3}$ água e $12 \mathrm{~m}^{3}$ esgoto } & 0 a 15 & 8,93 & 9,84 \\
\hline & 16 a 50 & 10,59 & 11,63 \\
\hline & $>50$ & 16,46 & 18,1 \\
\hline \multirow[t]{3}{*}{ Pública - Demanda mínima de $15 \mathrm{~m}^{3}$ água e $12 \mathrm{~m}^{3}$ esgoto } & 0 a 15 & 5,89 & 6,48 \\
\hline & 16 a 50 & 8,77 & 9,63 \\
\hline & $>50$ & 14,07 & 15,47 \\
\hline \multirow[t]{5}{*}{ Entidade Filantrópica - Demanda mínima de $10 \mathrm{~m}^{3}$ água e $8 \mathrm{~m}^{3}$ esgoto } & 0 a 10 & 2,83 & 2,83 \\
\hline & 11 a 15 & 4,76 & 4,76 \\
\hline & 16 a 20 & 5,12 & 5,12 \\
\hline & 21 a 50 & 8,77 & 8,77 \\
\hline & $>50$ & 15,47 & 15,47 \\
\hline
\end{tabular}

Observações: *Válida a partir de 24 de março de 2019 para Fortaleza e estado do Ceará, à exceção de Itapipoca. A demanda mínima serve para estimular o cliente a consumir um mínimo diário de água, necessário para sua sobrevivência, conforme cáculos da Organização Mundial de Saúde (OMS) para uma família de 5 pessoas.

Fonte: Site da CAGECE (2019).

dins do condomínio, foi realizado o cálculo de estimativa do volume de água drenada, à partir das informações do memorial descritivo do projeto, e comparado ao volume estimado necessário para irrigar os $1700 \mathrm{~m}^{2}$ de jardins, cerca de 5,75 litros por metro quadrado por dia, informação estimada por Martins, Diniz e Araújo (2015), a partir de levantamento experimental na região de Juazeiro do Norte no Ceará.

Para verificar a viabilidade técnica da água de drenagem no uso de irrigação dos jardins do condomínio, uma amostra foi submetida a ensaios laboratoriais. A amostra deve obedecer aos critérios estabelecidos pela Resolução CONAMA No 357, de 17 de março de 2005. Esta resolução dispõe sobre a classificação e diretrizes ambientais para o enquadramento dos corpos de água superficiais e estabelece condições e padrões de lançamento e utilização de efluentes. A Tabela 4 descreve as condições e padrões para águas doces de Classe 4, que engloba usos para harmonia paisagística, conforme Resolução no 357.
Para verificar a viabilidade econômica para o reuso da água captada pelo sistema de drenagem subterrânea na irrigação dos $1.700 \mathrm{~m}^{2}$ de jardim do condomínio, foi feita uma simulação de conta de cobrança da concessionária para um mês dessa atividade, utilizando os critérios da Tabela 3. O volume médio necessário para irrigação de jardins adotado para este cálculo é de 5,75 litros de água por metro quadrado por dia. Para o caso do condomínio em questão, a demanda diária é em torno de $10 \mathrm{~m}^{3}$.

Além do custo total de consumo de água e coleta de esgoto, foram acrescentados valores dos custos referentes a ensaios laboratoriais de amostras da água para monitoramento periódico de qualidade.

\section{Resultados e Discussões}

\subsection{Viabilidade técnica}

Conforme volume extraído do memorial de cálculo do projeto, o sistema de drenagem recolhe $1,64 \mathrm{~m}^{3} / \mathrm{h}$, o 
Tabela 4 - Condições e padrões para água utilizada em irrigação de jardins.

\begin{tabular}{lc}
\hline Parâmetros Resolução CONAMA No. 357 & Condições e Padrões (Classe $4 *$ ) \\
\hline Materiais flutuantes, inclusive espumas não naturais & Virtualmente ausentes** \\
Odor e aspecto & Não objetáveis \\
Óleos e graxas & Toleram-se iridescências \\
Substâncias facilmente sedimentáveis que contribuam para o assoreamento de canais de navegação & Virtualmente ausentes \\
Fenóis totais (substâncias que reagem com 4 - aminoantipirina) & $\leq 1,0 \mathrm{mg} / \mathrm{L} \mathrm{C} \mathrm{H}_{5} \mathrm{OH}$ \\
OD (Oxigênio Dissolvido) & $\geq 2,0 \mathrm{mg} / \mathrm{L} \mathrm{O} \mathrm{O}_{2}$ \\
pH & $6,0 \mathrm{a} 9,0$
\end{tabular}

Observações: *Classe 4: águas que podem ser destinadas à harmonia paisagística; **Virtualmente ausentes: que não é perceptível pela visão, olfato ou paladar.

Fonte: Adaptado da Resolução CONAMA No 357 (2005).

que gera um total de cerca de $39 \mathrm{~m}^{3}$ de água por dia. Esse volume garante, caso necessário, tanto o atendimento das atividades do canteiro de obras, que é de cerca de $10 \mathrm{~m}^{3}$ por dia, em média, considerando o volume de $280 \mathrm{~m}^{3}$ por mês; quanto a demanda para irrigação de jardins do condomínio, que também é de $10 \mathrm{~m}^{3}$ por dia, em média.

De acordo com laudo fornecido por laboratório contratado, a análise para potabilidade da água mostrou que a água captada pelo sistema de drenagem subterrânea não atende aos requisitos da Portaria $\mathrm{N}^{\circ}$ 5, de 2017, do MS para consumo humano, como descrito na Tabela 5. Portanto, não pôde ser reutilizada em refeitórios, vestiários e bebedouros do canteiro de obras.

A coluna 1 da Tabela 5 mostra os parâmetros que foram analisados pelo laboratório contratado, na coluna 2 os valores de referência da Portaria $N^{\circ} 5$ de 2017 e na coluna 3 os valores encontrados pelos ensaios laboratoriais, realizados conforme metodologia do Standard Methods for the Examination of Water and Wastewater 23 the Edition 2017 e em ambiente controlado de acordo com a ABNT NBR /ISO IEC 17025:2005 - Requisitos gerais para a competência de laboratórios de ensaio e calibração.
Os resultados da maior parte dos parâmetros analisados estão bem distantes dos limites estabelecidos na legislação, com exceção de nitrato, que atingiu 7,79 mg/L, e cloretos e bactérias heterotróficas que se aproximaram da metade do limite permitido. Já os indicadores de coliformes, ambos apresentaram resultados acima dos valores permitidos. Esses são os indicadores mais relevantes para a potabilidade da água, pois podem ocasionar doenças às pessoas. Portanto, a água analisada não é potável.

Embora a água analisada não seja considerada própria para o consumo humano, ao comparar os parâmetros obtidos no resultado da análise com os parâmetros da norma ABNT NBR 15900-1, a água se mostrou adequada para utilização no processo da fabricação de concreto e argamassas a base de cimento. A Tabela 6 apresenta o comparativo entre os valores obtidos no ensaio das amostras de água e os valores de referência normativa.

O Tabela 6 traz os requisitos (coluna 1) e seus limites (coluna 2), conforme ABNT NBR 15900-1. Nas colunas 3 e 4, respectivamente, estão os resultados da análise realizada em laboratório, conforme metodologia do Standard Methods for the Examination of Water and Waste-

Tabela 5 - Resultados do ensaio para determinação de potabilidade da amostra de água.

\begin{tabular}{|c|c|c|c|}
\hline Descrição dos Valores de Referência da Portaria N ${ }^{\circ}$ de 2017 & Valores de Referência da Portaria $\mathrm{N}^{\circ} 5$ de 2017 & Valores Encontrados & Situação \\
\hline Cloretos & $250 \mathrm{mg} / \mathrm{L}$ & $129,28 \mathrm{mg} / \mathrm{L}$ & Aprovado \\
\hline Cor Aparente & $15 \mu \mathrm{H}^{1}$ & $<0,20 \mathrm{Pt} / \mathrm{Co}$ & Aprovado \\
\hline Dureza Total & $500 \mathrm{mg} / \mathrm{L}$ & $121,42 \mathrm{mg} / \mathrm{L}$ & Aprovado \\
\hline Ferro Total & Inferior à $0,3 \mathrm{mg} / \mathrm{L}$ & $<0,05 \mathrm{mg} / \mathrm{L}$ & Aprovado \\
\hline Nitrato & $10 \mathrm{mg} / \mathrm{L}$ & $7,79 \mathrm{mg} / \mathrm{L}$ & Aprovado \\
\hline Nitrito & $1 \mathrm{mg} / \mathrm{L}$ & $0,02 \mathrm{mg} / \mathrm{L}$ & Aprovado \\
\hline $\mathrm{pH}$ & 6,0 a 9,5 & 6,71 & Aprovado \\
\hline Sódio & $200 \mathrm{mg} / \mathrm{L}$ & $82,00 \mathrm{mg} / \mathrm{L}$ & Aprovado \\
\hline Sólidos Totais Dissolvidos & $1000 \mathrm{mg} / \mathrm{L}$ & $259,00 \mathrm{mg} / \mathrm{L}$ & Aprovado \\
\hline Turbidez & $1 \mathrm{uT}^{2}$ & $<0,01$ & Aprovado \\
\hline Bactérias Heterotróficas & Inferior à $500 \mathrm{UFC}^{3} / \mathrm{mL}$ & $240,0 \mathrm{UFC} / \mathrm{mL}$ & Aprovado \\
\hline Coliformes Termotolerantes & Ausência em 100 mL & 70,0 UFC/ $100 \mathrm{~mL}$ & Reprovado \\
\hline Coliformes Totais & Ausência em 100 mL & $>500 \mathrm{UFC} / 100 \mathrm{~mL}$ & Reprovado \\
\hline
\end{tabular}

Observações: (1) Unidade Hazen (mgPt-Co/L), (2) Unidade de Turbidez, (3) Unidade Formadora de Colônia. 
Tabela 6 - Comparativo entre parâmetros da ABNT NBR 15900-1 e a análise da amostra.

\begin{tabular}{|c|c|c|c|}
\hline Descrição dos requisitos da ABNT NBR 15900 & Parâmetro requerido em norma $(\mathrm{mg} / \mathrm{L})$ & $\begin{array}{l}\text { Teor encontrado em análise } \\
(\mathrm{mg} / \mathrm{L})\end{array}$ & Situação \\
\hline Óleos e gorduras & Não mais do que traços visíveis & 15,50 & $\overline{\text { Aprovado }}$ \\
\hline Detergentes & Qualquer espuma deve desaparecer em $2 \mathrm{~min}$ & $<0,01$ & Aprovado \\
\hline Cor & Amarelo claro a incolor & $4,0 \mathrm{uH}$ & Aprovado \\
\hline Material sólido & $\leq 50.000$ & 439,00 & Aprovado \\
\hline Odor & Inodoro & NO & Aprovado \\
\hline Ácidos & $\mathrm{pH} \geq 5$ & 7,60 & Aprovado \\
\hline Matéria orgânica & Cor mais clara ou igual à solução padrão & 0,48 & Aprovado \\
\hline Cloretos (concreto protendido) & $\leq 500$ & 78,30 & Aprovado \\
\hline Sulfatos & $\leq 2.000$ & 81,64 & Aprovado \\
\hline Álcalis & $\leq 1.500$ & 113,56 & Aprovado \\
\hline Açúcares & $\leq 100$ & 18,31 & Aprovado \\
\hline Fosfatos $\left(\mathrm{P}_{2} \mathrm{O}_{5}\right)$ & $\leq 100$ & 0,04 & Aprovado \\
\hline Nitratos $\left(\mathrm{NO}_{3}\right)$ & $\leq 500$ & 19,84 & Aprovado \\
\hline Chumbo $\left(\mathrm{Pb}^{2+}\right)$ & $\leq 100$ & $<0,002$ & Aprovado \\
\hline Zinco $\left(\mathrm{Zn}^{2+}\right)$ & $\leq 100$ & $<0,005$ & Aprovado \\
\hline
\end{tabular}

Tabela 7 - Comparativo entre parâmetros da Resolução CONAMA Nº 357 e a análise da amostra.

\begin{tabular}{|c|c|c|c|}
\hline Parâmetros Resolução CONAMA No. 357 & $\begin{array}{l}\text { Condições e padrões } \\
(\text { Classe } 4 *)\end{array}$ & $\begin{array}{l}\text { Resultado da } \\
\text { análise }\end{array}$ & Situação \\
\hline Materiais flutuantes, inclusive espumas não naturais & $\begin{array}{l}\text { Virtualmente } \\
\text { ausentes** }\end{array}$ & Ausente & Aprovado \\
\hline Odor e aspecto & Não objetáveis & Intensidade 0 & Aprovado \\
\hline Óleos e graxas & $\begin{array}{l}\text { Toleram-se } \\
\text { iridescências }\end{array}$ & $2,6 \mathrm{mg} / \mathrm{L}$ & Aprovado \\
\hline $\begin{array}{l}\text { Substâncias facilmente sedimentáveis que contribuam para o assoreamento de canais de } \\
\text { navegação }\end{array}$ & Virtualmente ausentes & $<0,10 \mathrm{~mL} / \mathrm{L} \cdot \mathrm{h}$ & Aprovado \\
\hline Fenóis totais (substâncias que reagem com 4 - aminoantipirina) & $\leq 1,0 \mathrm{mg} / \mathrm{L} \mathrm{C}_{6} \mathrm{H}_{5} \mathrm{OH}$ & $<0,009 \mathrm{mg} / \mathrm{L}$ & Aprovado \\
\hline OD (Oxigênio Dissolvido) & $\geq 2,0 \mathrm{mg} / \mathrm{L} \mathrm{O}_{2}$ & $4,10 \mathrm{mg} / \mathrm{L}$ & Aprovado \\
\hline $\mathrm{pH}$ & 6,0 a 9,0 & 7,18 & Aprovado \\
\hline
\end{tabular}

Observações: * Classe 4: águas que podem ser destinadas à harmonia paisagística, ** Virtualmente ausentes: que não é perceptível pela visão, olfato ou paladar.

water 23 the Edition 2017, e a situação relativa ao resultado.

Pode-se notar que alguns parâmetros encontrados na Tabela 6 também estão presentes na Tabela 5, porém com resultados distintos. Isso ocorre porque os ensaios foram realizados em épocas diferentes e por se tratar de uma fonte de água subterrânea, onde aquíferos são constantemente alimentados por outros corpos d'água ou por precipitação, suas características físico-químicas e microbiológicas podem sofrer alterações sem previsibilidade.

Para a análise de amostra relativa aos parâmetros da Resolução CONAMA No 357, de 2005, a Tabela 7 mostra o comparativo entre os padrões exigidos e os valores encontrados. O resultado é tecnicamente viável, conforme laudo apresentado por empresa contratada.

\subsection{Viabilidade econômica}

Segundo a construtora, o período de execução da obra é estimado em 60 meses. O que significa dizer que os serviços de canteiro de obras, que não exigem água potável, devem consumir algo em torno de $13.920 \mathrm{~m}^{3}$ de água ao longo dos 60 meses. A Tabela 8 mostra a estimativa de valor que deve ser economizado com o reuso da água.

A composição da conta de consumo descrita na Tabela 8 , se dá por faixas de volume. Na linha 1 , é preenchido apenas o volume referente aos 15 primeiros metros cúbicos consumidos, ou seja, caso um cliente da categorial industrial venha a consumir apenas $12 \mathrm{~m}^{3}$, o seu volume total é tarifado pelo valor da linha 1 , considerando o mínimo de $15 \mathrm{~m}^{3}$. Assim, o cliente consumidor industrial tem uma tarifa mínima mensal de R \$252,03, mesmo que venha a consumir um pouco menos. Já para as linhas 2 e 3 
Tabela 8 - Cálculo da fatura mensal e do valor total gasto com água no canteiro de obras.

\begin{tabular}{|c|c|c|c|c|c|c|c|}
\hline $\begin{array}{l}\text { Categoria } \\
\text { cliente }\end{array}$ & $\begin{array}{c}\text { Faixa de } \\
\text { demanda }\left(\mathrm{m}^{3}\right)\end{array}$ & $\begin{array}{l}\text { Tarifa água } \\
\left(\mathrm{R} \$ / \mathrm{m}^{3}\right)\end{array}$ & $\begin{array}{l}\text { Tarifa esgoto } \\
\qquad\left(\mathrm{R} \$ / \mathrm{m}^{3}\right)\end{array}$ & $\begin{array}{c}\text { Volume médio } \\
\text { mensal: água }\left(\mathrm{m}^{3}\right)\end{array}$ & $\begin{array}{c}\text { Volume médio } \\
\text { mensal: esgoto }\left(\mathrm{m}^{3}\right)\end{array}$ & $\begin{array}{c}\text { Valor médio } \\
\text { mensal: água (R\$) }\end{array}$ & $\begin{array}{c}\text { Valor médio mensal: } \\
\text { esgoto }(\mathrm{R} \$)\end{array}$ \\
\hline \multirow[t]{3}{*}{ Industrial } & 0 a 15 & 8,93 & 9,84 & 15 & 12 & 133,95 & 118,08 \\
\hline & 15 a 50 & 10,59 & 11,63 & 35 & 28 & 370,65 & 325,64 \\
\hline & $>50$ & 16,46 & 18,10 & 182 & 146 & $2.995,72$ & $2.642,60$ \\
\hline \multicolumn{6}{|c|}{ Total da fatura mensal estimada $(\mathrm{R} \$)$} & \multicolumn{2}{|c|}{$6.586,64$} \\
\hline \multicolumn{6}{|c|}{ Duração da obra } & \multicolumn{2}{|c|}{60 meses } \\
\hline \multicolumn{6}{|c|}{ Custo de monitoramento nos primeiros 6 meses - 6 análises $(\mathrm{R} \$)$} & \multicolumn{2}{|c|}{$4.500,00$} \\
\hline \multicolumn{6}{|c|}{ Custo de monitoramento semestral até o fim do período - 9 análises (R\$) } & \multicolumn{2}{|c|}{$6.750,00$} \\
\hline \multicolumn{6}{|c|}{ Valor total estimado gasto com água tratada no período menos custo de monitoramento (R\$) } & \multicolumn{2}{|c|}{$225.869,04$} \\
\hline
\end{tabular}

da tabela, o volume cobrado é apenas o excedente da soma das linhas anteriores, sendo que na linha 2 o volume máximo a ser tarifado é de $35 \mathrm{~m}^{3}$ e na linha 3 o volume excedente aos $50 \mathrm{~m}^{3}$, resultantes do somatório das linhas 1 e 2 . Na coluna 6, são computados os valores correspondentes ao volume de esgoto gerado, considerado estes como sendo $80 \%$ do volume de água consumida, mesmo que a geração de esgoto seja maior, menor ou nenhuma.

Dessa forma, o gasto utilizando água proveniente da concessionária pública para a execução do empreendimento em questão é de aproximadamente R\$ 225.869,04. Este valor está sendo economizado com a implantação do sistema de aproveitamento de água da drenagem subterrânea. Isso significa uma economia de $0,21 \%$ sobre o valor total orçado da obra $(\mathrm{R} \$ 105.937 .508)$, de acordo com dados fornecidos pela construtora.

Para o reuso da água de drenagem na irrigação dos jardins do empreendimento após a entrega, o volume de água estimado para essa atividade é de cerca de $294 \mathrm{~m}^{3}$ por mês, considerando uma necessidade de $5,75 \mathrm{~L} / \mathrm{m}^{2}$ em 30 dias, para sua área de $1.700 \mathrm{~m}^{2}$. A conta simulada foi para o período de um mês, pois não é possível estabelecer um tempo de uso definido, como o da análise anterior, visto que o volume de água necessário para manter o jardim pode variar com a ocorrência de chuvas e com períodos de umidade do ar mais baixa; como também o volume de água drenado pelo sistema pode baixar a ponto de não atender à necessidade. Apesar de essa última opção não ter um risco alto, pois além do volume diário drenado ser maior do que o dobro da necessidade, o condomínio dispõe de um segundo sistema de drenagem semelhante e instalado na Torre A, que não entrou neste estudo, e cujo potencial é o mesmo. O resultado está apresentado na Tabela 2 .

A composição da conta de consumo descrita na Tabela 9, se dá por faixas de volume, da mesma forma que no modelo industrial, descrito na análise anterior. Na linha 1 , é preenchido apenas o volume referente aos 10 primeiros metros cúbicos consumidos, ou seja, caso um cliente da categoria residencial venha a consumir apenas $7 \mathrm{~m}^{3}$, o seu volume total é tarifado pelo valor da linha 1 , com o volume mínimo de $10 \mathrm{~m}^{3}$, gerando uma conta mensal mínima de $\mathrm{R} \$ 75,98$, resultado do somatório das tarifas totais de água e esgoto das colunas 7 e 8, respectivamente. Já para as linhas que se seguem, de 2 a 5, da Tabela 9, o volume computado é apenas o excedente do somatório das linhas anteriores. Sendo que nas linhas 2 e 3 o volume máximo a ser tarifado é de $5 \mathrm{~m}^{3}$, na linha 4 o volume máximo é de $30 \mathrm{~m}^{3}$ e na linha 5 o volume excedente aos $50 \mathrm{~m}^{3}$, resultantes do somatório das linhas 1 a 4 . Na coluna 6, são computados os valores correspondentes ao volume de esgoto gerado, considerado estes como sendo $80 \%$ do volume de água consumida, mesmo que a geração de esgoto seja maior, menor ou nenhuma.

Desta forma, se o condomínio fosse utilizar água tratada e fornecida pela concessionária para irrigar os cerca

Tabela 9 - Cálculo da fatura mensal e do valor total economizado com água para irrigação de jardins.

\begin{tabular}{|c|c|c|c|c|c|c|c|}
\hline $\begin{array}{l}\text { Categoria } \\
\text { cliente }\end{array}$ & $\begin{array}{c}\text { Faixa de } \\
\text { demanda }\left(\mathrm{m}^{3}\right)\end{array}$ & $\begin{array}{c}\text { Tarifa água } \\
\left(\mathrm{R} \$ / \mathrm{m}^{3}\right)\end{array}$ & $\begin{array}{l}\text { Tarifa esgoto } \\
\left(\mathrm{R} \$ / \mathrm{m}^{3}\right)\end{array}$ & $\begin{array}{l}\text { Volume médio men- } \\
\text { sal de água }\left(\mathrm{m}^{3}\right)\end{array}$ & $\begin{array}{l}\text { Volume médio } \\
\text { mensal de esgoto } \\
\left(\mathrm{m}^{3}\right)\end{array}$ & $\begin{array}{c}\text { Valor médio } \\
\text { mensal de água } \\
(\mathrm{R} \$)\end{array}$ & $\begin{array}{c}\text { Valor médio mensal } \\
\text { de esgoto (R\$) }\end{array}$ \\
\hline \multirow{7}{*}{$\begin{array}{l}\text { Residencial } \\
\text { Normal }\end{array}$} & 0 a 10 & 4,03 & 4,46 & 10 & 8 & 40,3 & 35,68 \\
\hline & 16 a 20 & 5,65 & 6,20 & 5 & 4 & 28,25 & 24,8 \\
\hline & 21 a 50 & 9,69 & 10,65 & 30 & 24 & 290,7 & 255,6 \\
\hline & $>50$ & 17,11 & 18,82 & 244 & 196 & 4174,84 & 3688,72 \\
\hline & \multicolumn{5}{|c|}{ Total da fatura mensal estimada (R\$) } & \multicolumn{2}{|c|}{$8.587,92$} \\
\hline & \multicolumn{5}{|c|}{ Custo de monitoramento bimestral (R\$/mês) } & \multicolumn{2}{|c|}{150,00} \\
\hline & \multicolumn{5}{|c|}{ Valor total estimado gasto com água tratada na irrigação do jardim (R\$) } & \multicolumn{2}{|c|}{$8.437,92$} \\
\hline
\end{tabular}


de $1.700 \mathrm{~m}^{2}$ de jardim, geraria um incremento em suas despesas mensais com água e esgoto de $\mathrm{R} \$ 8.437,92$. Esse valor pode corresponder a uma economia da ordem de cem mil reais por ano no orçamento do condomínio.

Essa cobrança indiscriminada da concessionária na geração de esgoto, fortalece o ganho de economia em casos de reuso de água como insumo na indústria da construção civil e irrigação de jardins, pois nesses casos a água é totalmente consumida no processo sem geração de esgoto. Assim, em ambos os casos o consumidor acaba sendo duplamente taxado, pois paga pela água consumida e pelo esgoto não gerado.

Já para o reuso da água de drenagem em atividades do canteiro em que ela entra em contato com o cimento, os parâmetros são mais específicos e merecem bastante atenção, principalmente o teor de cloretos e álcalis, eles podem causar baixa durabilidade aos concretos e argamassas. Por isso, é imprescindível que os ensaios periódicos sejam realizados rigorosamente a cada mês, nos primeiros seis meses, para que se tenha um perfil característico dessa água, e depois a cada seis meses, para que não haja prejuízos ao produto.

A redução de gastos com água no canteiro parece pouco representativa, apenas $0,21 \%$ no orçamento total. Ainda mais se for levado em consideração que as empresas não incluem a água como sendo um insumo com custo de aquisição nas composições de preço unitário dos serviços. Um bom exemplo disso é a composição de custo unitário do concreto de $30 \mathrm{MPa}$ da Tabela de Custos da Seinfra-CE (Secretaria de Infraestrutura do Estado do Ceará), que é amplamente utilizada em orçamentos no estado. Veja seu custo detalhado na Fig. 3.

Nota-se que, dentre os materiais listados, a água utilizada para a fabricação ou amassamento do concreto não é contabilizada, apesar de ser uma quantidade razoável, algo em torno de 170 litros por $\mathrm{m}^{3}$. Para esse volume de água, aplicando a tarifa média da categoria industrial ( $\mathrm{R} \$ 10,56$ de água $+\mathrm{R} \$ 9,30$ para $80 \%$ de esgoto), teria um custo de aproximadamente $\mathrm{R} \$ 19,86 / \mathrm{m}^{3}$ e, para $1 \mathrm{~m}^{3}$ de concreto, $R \$ 3,38$. Isso significa $0,85 \%$ de incremento no custo unitário do concreto de $30 \mathrm{MPa}$.

A conta para os $294 \mathrm{~m}^{3}$ não utilizados na irrigação dos jardins do condomínio é semelhante. Conforme CAGECE (2020), esse volume seria suficiente para abastecer 29 famílias. O seu impacto financeiro dessa redução no consumo de água do condomínio é interessante. $\mathrm{O}$ valor de $\mathrm{R} \$ 8.437,92$ é suficiente para suprir os custos de 3 funcionários, remunerados com salário-mínimo, segundo Jornal Contábil (2019).
Tabela de Custos - Versão 026 - ENC. SOCIAIS 114,23\%

C0844 - CONCRETO PNIBR., FCK 30 MPa COM AGRECADO ADQUIRIDO

Preço Adotado: 396,2800

Unid: M3

\begin{tabular}{|llcrrr|}
\hline Código & Descriçăo & $\begin{array}{c}\text { Unidade } \\
\text { MATERIAIS }\end{array}$ & Coeficiente & Preço & Total \\
\hline 11605 & PEDRISCO & M3 & 0,2090 & 69,7500 & 14,5778 \\
10805 & CIMENTO PORTLAND & KG & 396,0000 & 0,4600 & 182,1600 \\
10109 & AREIA MEDIA & M3 & 0,9290 & 51,0000 & 47,3790 \\
10280 & BRITA & M3 & 0,6270 & 76,7500 & 48,1222
\end{tabular}

TOTAL MATERIAIS

292,2390

\begin{tabular}{|lccrrr}
\hline \multicolumn{5}{c}{ EQUIPAMENTOS (CHORARIO) } \\
\hline 10682 & BETONEIRA ELÉTRICA 580L (CHP) & H & 0,7140 & 21,6837 & 15,4822
\end{tabular}

TOTAL EQUIPAMENTOS (CHORARIO) $\quad 15,4822$

\begin{tabular}{|l|r|r|r|}
\hline MAO DE OBRA & & \\
\hline H 2543 SERVENTE & 6,0000 & 14,7600 & 88,5600 \\
& TOTAL MAO DE OBRA & $\mathbf{8 8 , 5 6 0 0}$ \\
& Total Simples & 396,28 \\
& Encargos & INCLUSOS \\
& BDI & 0,00 \\
& TOTAL GERAL & $\mathbf{3 9 6 , 2 8}$
\end{tabular}

Figure 3 - Composição de custo unitário de concreto de 30 MPa. Fonte: Secretaria de Infraestrutura do Ceará (2020). 
Mesmo a água do sistema de drenagem não atendendo aos parâmetros de potabilidade, a geração de valor agregado com o seu reuso nas atividades do canteiro de obras, que não exigem potabilidade, e na irrigação dos jardins, é representativa. Essa água demonstrou ter grande potencial econômico, social e de sustentabilidade, gerando economia nas despesas da execução de obra, redução substancial nas despesas com água e esgoto do condomínio e, ainda, uma redução significativa no consumo de água tratada em atividades que não exigem essa especificidade.

\section{Considerações Finais}

Esta pesquisa propôs um estudo de viabilidade técnica e econômica do reuso de água proveniente de drenagem subterrânea profunda, instalada no subsolo de um empreendimento em construção, em atividades de um canteiro de obras, primeiramente, e na irrigação de jardins do condomínio após sua construção.

Dentro do contexto geográfico, considerando que o empreendimento está situado na cidade de Fortaleza-CE, sabe-se que se trata de uma localização muito próxima de áreas semiáriadas, mas também servida de uma extensa faixa litorânea, que contribui com a manutenção dos corpos hídricos subterrâneos. Na região do bairro onde o empreendimento se encontra, é possível observar condomínios semelhantes, construídos há mais de 15 anos, cujos sistemas de drenagem subterrânea profunda continuam em operação constante. Isto posto, considero que o sistema de drenagem oferece alguma segurança à sustentabilidade deste reuso, visto que a capacidade de captação do sistema consegue gerar, em estimativa de projeto, cerca de $29 \mathrm{~m}^{3}$ por dia, quase o triplo do volume demandado para ambos os casos, cerca de $10 \mathrm{~m}^{3}$ por dia. Naturalmente, podem acontecer dias ou épocas em que essa margem não exista ou seja negativa. Já para o caso da irrigação, esse fenômeno de consumo muito maior que a captação é mais improvável, pois além do volume ser mais próximo da constância, ele ainda pode ser divido por dois ou três estágios de irrigação durante o dia. Considerando que sistemas planejados de irrigação nunca despejam o volume total necessário de uma só vez no jardim.

Os resultados obtidos nas análises laboratoriais de qualificação das amostras de água para os respectivos fins, foram dentro do esperado. Não se espera encontrar água potável em um aquífero raso, que sofre influência atmosférica direta, como é o caso deste do estudo. Aquíferos que tem contato direto com corpos hídricos superficiais estão mais sujeitos a contaminação bacteriana, pois tem interferência de animais e antrópica, muitas vezes com deposição de resíduos sem o devido controle. Por isso, já era esperado que a água não se qualificasse como potável, restringindo, assim, seu uso apenas a atividades que não envolvem o consumo humano.
Quanto a qualificação para a irrigação, os critérios são menos rigorosos do que a análise de potabilidade, portanto maior a probabilidade de a amostra ser aprovada, como de fato foi. Um sistema de drenagem como este do estudo funciona como um filtro, pois a água passa por camadas de agregados, primeiro uma de brita 03 e depois uma de areia grossa, e depois por um elemento filtrante, parecido com um tecido, que é o Bidin RT 10. Esse elemento filtrante tem malha com abertura aparente de $0,100 \mathrm{~mm}$ e fluxo de água de $100 \mathrm{~L} / \mathrm{s}$ (por metro quadrado). Apesar da vazão ser alta, como a malha é muito pequena, a capacidade de retenção de material sólido sedimentável, materiais flutuantes, óleos e gorduras é boa. Logo, as chances de essas características permanecerem dentro dos padrões estabelecidos pela legislação são boas. Contudo, não deve ser ignorada a recomendação de que se realize um ensaio a cada dois meses.

Já para o reuso da água de drenagem em atividades do canteiro em que ela entra em contato com o cimento, os parâmetros são mais específicos e merecem bastante atenção, principalmente o teor de cloretos e álcalis, eles podem causar baixa durabilidade aos concretos e argamassas. Por isso, é imprescindível que os ensaios periódicos sejam realizados rigorosamente a cada mês, nos primeiros seis meses, para que se tenha um perfil característico dessa água, e depois a cada seis meses, para que não haja prejuízos ao produto.

Para trabalhos futuros, recomenda-se avaliar a viabilidade técnica e financeira para utilização de água armazenada em poços de drenagem subterrânea de condomínios residenciais, já em operação, que apresentam um sistema permanente de rebaixamento de lençol freático instalado, a fim de utilizar esta água para irrigação de jardins ou outros fins. E, para condomínios ainda em desenvolvimento de projeto, avaliar a possibilidade de reuso dessa água para outros serviços, como por exemplo: descargas de bacias sanitárias e lavagem de roupas.

\section{Referências}

ASSOCIAÇÃO BRASILEIRA DE NORMAS TÉCNICAS. NBR 15900-1: Água Para Amassamento de Concreto Parte 1: Requisitos. Rio de Janeiro: ABNT, 2009.

BRASIL. Lei ${ }^{\circ}$ 9.433, de 08 de janeiro de 1997. Institui a Política Nacional de Recursos Hídricos. Brasília: Presidência da República - Casa Civil, 1997. Disponível em: http://www.planalto.gov.br/ccivil_03/Leis/L9433.htm. Acesso em: 01 set. 2019.

CAGECE - COMPANHIA DE ÁGUA E ESGOTO DO CEARÁ. Resolução $N^{\circ}$ 012/16/DPR: Estrutura Tarifária de Água e Esgoto, no Estado do Ceará à Exceção de Itapipoca. Disponível em https://www.cagece.com.br/wp-content/ uploads/PDF/HistoricoTarifas/2016-Resolu\%C3\%A7\% C3\%A3o-012-16-Revis\%C3\%A3o-Extraordin\%C3\% A1ria-Cear\%C3\%A1.pdf. Acesso em 15 de abr. 2020. 
CBIC - CÂMARA BRASILEIRA DA INDÚSTRIA DA CONSTRUÇÃO. Gestão de Recursos Hídricos na Indústria da Construção: Conservação de Água e Gestão de Demanda. Brasília: CBIC, 2017. Disponível em https://cbic. org.br/wp-content/uploads/2017/11/Gestao_de_Recur sos_Hidricos_na_Industria_da_Construcao_2017-1.pdf. Acesso em 3 de set. 2019.

CONAMA- CONSELHO NACIONAL DO MEIO AMBIENTE. Resolução $n^{\circ}$ 357, de 18 de março de 2005. Dispõe sobre a classificação dos corpos de água e diretrizes ambientais para o seu enquadramento, bem como estabelece as condições e padrões de lançamento de efluentes. Brasília: CONAMA, 2005. Disponível em http://www2.mma.gov. br/port/conama/legiabre.cfm?codlegi $=459$. Acesso em 11 dez. 2019.

JORNAL CONTÁBIL. Quanto Custa Um Funcionário Para Uma Empresa? 2019. Disponível em https://www.jornal contabil.com.br/quanto-custa-um-funcionario-para-umaempresa/. Acesso em 15 ago. 2020.

MANCUSO, P.; SANTOS, H.F. Reuso de Água. Barueri: Manole, 2003.

MARTINS, E.G.O.; DINIZ, A.M.F.; ARAÚJO, R.D. Irrigação com aproveitamento da água das chuvas e bombeamento fotovoltaico. In: V Congresso Brasileiro de Engenharia de Produção, Ponta Grossa, 2015. Disponível em https:// www.researchgate.net/publication/303636726_Irrigacao_ com_aproveitamento_da_agua_das_chuvas_e_bombeamen to_fotovoltaico. Acesso em 30 jul. 2020.
MARQUES, C.T.; GOMES, B.M.F.; BRANDLI, L.L. Consumo de água e energia em canteiros de obra: um estudo de caso do diagnóstico a ações visando à sustentabilidade. Ambient. Constr., v. 17, n. 4, p. 79-90, 2017.

MINISTÉRIO DA SAÚDE. Portaria de Consolidação $\mathbf{n}^{\circ} \mathbf{5}$, de 28 de Setembro de 2017. Consolidação das normas sobre as ações e os serviços de saúde do Sistema Único de Saúde. Brasília: Ministério da Saúde, 2017. Disponível em http:// bvsms.saude.gov.br/bvs/saudelegis/gm/2017/ prc0005_03_10_2017.html. Acesso em 5 maio 2020.

MINISTÉRIO DO MEIO AMBIENTE. 2020. Água. Disponível em https://www.mma.gov.br/estruturas/secex_consumo/ arquivos/3\%20-\%20mcs_agua.pdf. Acesso em 2 abr. 2020.

MINISTÉRIO DO MEIO AMBIENTE. 2020. Construções Sustentáveis. Disponível em http://a3p.mma.gov.br/con strucoes-sustentaveis/. Acesso em 2 abr. 2020.

SECRETARIA DE INFRAESTRUTURA DO CEARÁ (SEINFRA). Tabela de Custos. 2020. Disponível em https://sites. seinfra.ce.gov.br/siproce/onerada/html/C0844.html? $\mathrm{a}=1545419674041$. Acesso em 15 ago. 2020.

TELlES, D.D'A.; COSTA, R.H.P.G. Reuso da Água: Conceitos, Teorias e Práticas. 2 ed. São Paulo: Blucher, 2010.

License information: This is an open-access article distributed under the terms of the Creative Commons Attribution License (type CC-BY), which permits unrestricted use, distribution and reproduction in any medium, provided the original article is properly cited. 